ORIGINAL RESEARCH

\title{
Incidence and Characteristics of Snakebite Envenomations in the New York State Between 2000 and 2010
}

\author{
Jeremy D. Joslin, MD; Jeanna M. Marraffa, PharmD; Harinder Singh, MD; Joshua Mularella, DO \\ From the Department of Emergency Medicine, State University of New York Upstate Medical Center, Syracuse, NY (Drs Joslin, Marraffa, and \\ Mularella), and the Department of Emergency Medicine, Beth Israel Medical Center, New York, NY (Dr Singh).
}

\begin{abstract}
Objective.-We sought to evaluate the incidence of reported venomous snakebites in the state of New York between 2000 and 2010.

Methods.-Data were collected retrospectively from the National Poison Data System (NPDS) and then reviewed for species identification and clinical outcome while using proxy measures to determine incidence of envenomation.

Results.-From 2000 to 2010 there were 473 snakebites reported to the 5 Poison Control Centers in the state of New York. Venomous snakes accounted for 14.2\% (67 of 473) of these bites. Only 35 bites $(7 \%)$ required antivenom. The median age of those bitten by a venomous snake was 33 . Most victims were male.

Conclusions.-Although not rare, venomous snakebites do not occur commonly in New York State, with a mean of just 7 bites per year; fortunately most snakebites reported are from nonvenomous snakes. Yet even nonvenomous bites have the potential to cause moderately severe outcomes. Medical providers in the state should be aware of their management.
\end{abstract}

Key words: envenomations, Northeast, New York, snakebites

\section{Introduction}

There are approximately 120 species of snakes in the United States, approximately 20 of which are venomous. Except for the coral snake, all venomous snakes belong to the subfamily Crotalinae (pit vipers) and are represented by at least one species in every state except Alaska, Maine, and Hawaii. ${ }^{1}$ There is no central reporting system for snakebite envenomations, and in the past various databases have been used at both the national and state level to report the incidences of their envenomations.

A query of the Centers for Disease Control and Prevention (CDC) Wonder database from 1991 to 2001, which tracks all fatalities in this country, found a total of 57 deaths attributed to snakebites, only 2 of which were in the Northeast. ${ }^{2}$ Another study reviewed the CDC's National Electronic Injury Surveillance System-All Injury Program (NEISS-AIP) data for all visits to US emergency departments from 2001 to 2004

Corresponding author: Jeremy D. Joslin, MD, Department of Emergency Medicine, State University of New York Upstate Medical Center, 550 East Genesee Street, EMSTAT Center, Syracuse, NY 13202 (e-mail: joslinj@upstate.edu). related to snakebites. ${ }^{3}$ They found that during those 4 years there were a total of 3188 bites from venomous snakes. The American Association of Poison Control Centers (AAPCC) annual report for 2011 lists 3663 cases related to Crotalinae bites, resulting in only 2 deaths. ${ }^{4}$

The epidemiology and characteristics of Crotalinae envenomations have also been well documented in several states across the United States such as Arizona, Texas, and other Southern states where venomous snakes are more common. ${ }^{5-8}$ However, in states like New York where envenomations by snakes are relatively rare, there is a paucity of epidemiologic literature. Although snakebite envenomations are uncommon to medical practitioners in New York, they do sporadically occur and therefore should be a component of education and training.

We sought to review all snakebite envenomations reported to the 5 regional poison centers in New York State between 2000 and 2010. At the time of the data collection, poison centers were located in New York City (New York City Regional Poison Control Center), Syracuse (Central New York Regional Poison Control Center), Long Island (Long Island Regional Poison and 
Drug Information Center), Rochester (Finger Lakes Regional Poison and Drug Information Center), and Buffalo (Western New York Regional Poison Control Center). Although exact numbers are not published, it is reported by coauthor J. Marraffa that poison centers in New York State receive approximately 150,000 calls annually (personal communication, December 2013).

\section{Methods}

This retrospective review was granted exemption status by the SUNY Upstate Medical Center Institutional Review Board based on methodologies and study nature (226640-3). All 5 poison centers in New York State electronically submit data to the National Poison Data System (NPDS) in a standardized, patient deidentified format.

The NPDS database was queried for all cases between 2000 and 2010 in the state of New York in which a snakebite had occurred. The NPDS was searched using human exposures and the AAPCC generic code for snakebite from January 1, 2000, through December 31, 2010. Each case was then analyzed by year of the incident, age, sex, poison control center (PCC), species of reported snake, management site, treatment, and outcome category. Envenomations in which the case originated in another state but was reported to a New York PCC were excluded. The Figure shows the catchment area of each of the poison centers used in this analysis.

Data was standardized with regards to snake identification and envenomation. For example, family, genus,

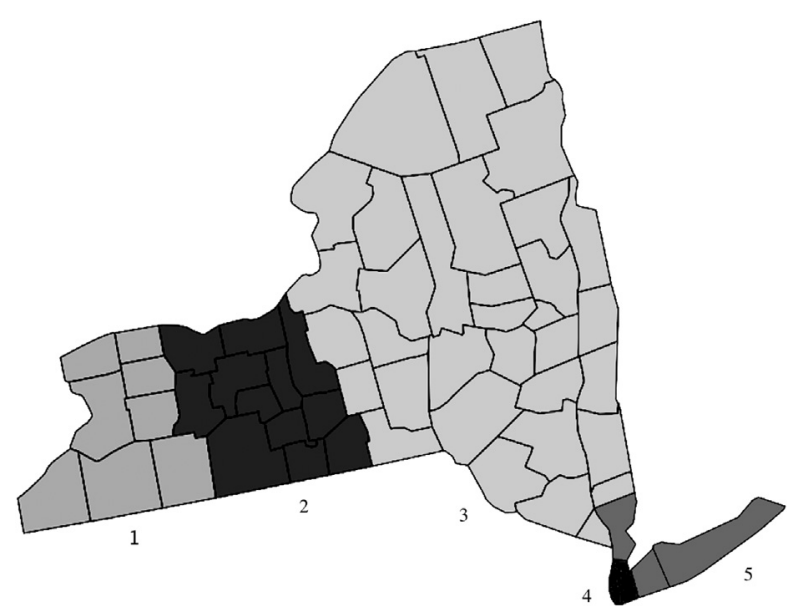

Figure. New York State poison control centers and their catchment area by county: Western New York Regional Poison Control Center (1), Finger Lakes Regional Poison and Drug Information Center (2), Central New York Regional Poison Control Center (3), New York City Regional Poison Control Center (4), and Long Island Regional Poison and Drug Information Center (5). or species of the snake was included when reported in the database; otherwise the highest taxonomic category was used. Patients who received antivenom were assumed to have been bitten by a venomous snake and categorized as such for this study. Limited characteristics of envenomation treatment were provided in the query and included.

All local PCCs employ Specialists in Poison Information (SPI). These are generally registered nurses or pharmacists who provide consultation via telephone to triage and assess potentially toxic exposures and provide recommendations based on the nature of the exposure and the anticipated outcome severity. ${ }^{9}$ The clinical effects and outcome category of each case are recorded by an SPI at the respective PCC at the time of case closure. The medical outcome is the final determination made by the SPI based on all of the information available and the clinical effects identified.

The coding and medical outcome definitions are created by the AAPCC and thereby are consistent among the regional poison centers. The medical outcome codes included the following:

- Unrelated: the exposure was not responsible for the clinical effect.

- Not followed: clinical judgment determined that the exposure was likely to result only in minimal toxicity of a trivial nature.

- Confirmed nonexposure: reliable and objective evidence exists that the exposure never occurred and the patient never exhibited symptoms related to the reported exposure.

- No effect: the patient developed no symptoms as a result of the exposure.

- Minor effect: the patient exhibited some symptoms as a result of the exposure; the symptoms however were minimally bothersome to the patient and improve rapidly.

- Moderate effect: the patient exhibited symptoms as a result of the exposure and the symptoms were more pronounced, more prolonged, or more of a systemic nature; often, some kind of treatment is required.

- Major effect: the patient exhibited symptoms as a result of the exposure, which were life-threatening or resulted in significant residual disability.

- Death: the patient died as a result of the exposure or a direct complication of the exposure.

\section{Results}

A total of 473 human snakebites were reported to the 5 New York State poison control centers in operation between 2001 and 2010. Most snakebites were reported 
Table 1. Characteristics and management of all snakebites

\begin{tabular}{|c|c|c|c|c|}
\hline Variable & Total bites & Venomous bites & Percent of all bites & Percent of venomous bites \\
\hline \multicolumn{5}{|l|}{ Cases by species } \\
\hline Copperhead & 25 & & 5.3 & 37.3 \\
\hline Cottonmouth & 3 & & 0.6 & 4.5 \\
\hline Eastern diamondback rattlesnake & 1 & & 0.2 & 1.5 \\
\hline Prairie rattlesnake & 1 & & 0.2 & 1.5 \\
\hline Timber rattlesnake & 3 & & 0.6 & 4.5 \\
\hline Rattlesnake, NOS & 12 & & 2.5 & 17.9 \\
\hline Pit viper, NOS & 16 & & 3.4 & 23.9 \\
\hline Venomous, NOS & 6 & & 1.3 & 9.0 \\
\hline Venomous subtotal & 67 & & 14.2 & \\
\hline Unknown (considered nonvenomous) & 163 & & 34 & \\
\hline Coded nonvenomous & 243 & & 51.4 & \\
\hline Total & 473 & & & \\
\hline \multicolumn{5}{|l|}{ Cases by PCC } \\
\hline New York City & 97 & 19 & 20.5 & 28.4 \\
\hline Long Island & 103 & 8 & 21.8 & 11.9 \\
\hline Rochester & 35 & 3 & 7.4 & 4.5 \\
\hline Buffalo & 17 & 1 & 3.6 & 1.5 \\
\hline Upstate & 221 & 36 & 46.7 & 53.7 \\
\hline Total & 473 & 67 & & \\
\hline \multicolumn{5}{|l|}{ Management } \\
\hline Received antivenom & 35 & 35 & 7.4 & 52.2 \\
\hline Received antihistamines & 10 & 7 & 2.1 & 10.4 \\
\hline Received antibiotics & 39 & 10 & 8.2 & 14.9 \\
\hline Received steroids & 7 & 7 & 1.5 & 10.4 \\
\hline Total & 91 & 59 & & \\
\hline \multicolumn{5}{|l|}{ Outcome severity } \\
\hline Major & 8 & 8 & 1.7 & 11.9 \\
\hline Moderate & 204 & 27 & 43.1 & 40.3 \\
\hline Minor & 65 & 19 & 13.7 & 28.4 \\
\hline No effect & 23 & 2 & 4.9 & 3.0 \\
\hline Not followed & 135 & 1 & 28.5 & 1.5 \\
\hline Unable to follow & 31 & 8 & 6.6 & 11.9 \\
\hline Confirmed nonexposure & 2 & 0 & 0.4 & 0 \\
\hline Unrelated effect & 5 & 2 & 1.1 & 3.0 \\
\hline Total & 473 & 67 & & \\
\hline
\end{tabular}

NOS, not otherwise specified; PCC, poison control center.

to be specifically nonvenomous bites (243 of 473; $51.4 \%$ ) or reported bites by an unknown snake and abstracted as nonvenomous (163 of 473; 34\%). Only $14.2 \%$ (67 of 473 ) of these snakebites were reported or abstracted as bites by a venomous snake. The median number of venomous bites per year was 7 with a range of 1 (years 2000, 2001) through 11 (year 2002) venomous bites reported statewide.

The median age of all persons with reported snakebite was 17 years (range, 2-89 years), while those reported with venomous snakebite was 33 years (range, 4-86 years). Males (53 of $67 ; 79 \%$ ) were more likely to be bitten by a venomous snake than females, and males were also responsible for more bites overall irrespective of venomous status (323 of 473; 68\%). The Table describes all reported bites categorized by offending snake, poison control center, outcomes, and management.

Nonvenomous snakebites reported in the NPDS dataset during the time frame we reviewed implicated the following snakes: Python spp, Thamnophis spp, Elaphe spp, Epicrates spp, Elaps (Homoroselaps) spp, Lampropeltis spp, Cerberus spp, Lichanura spp, Diadophis spp, Morelia spp, Nerodia spp, Epicrates spp, and Candoia spp.

\section{Discussion}

Although they occur less frequently than in other regions of the United States, snakebite envenomations do occur 
in the state of New York. We sought to estimate the incidence of these venomous snakebites by retrospectively reviewing and abstracting Poison Control Center Data via published NPDS data. As in any retrospective study, our review of the NPDS data suffers from limitations of reporting bias, selection bias, and possible confounders that cannot be controlled; however, the use of NPDS data for analyzing the incidence of snakebites and their characteristics has precedent in the medical literature despite these shortcomings. ${ }^{10}$ O'Neil et $\mathrm{al}^{3}$ used the National Electronic Injury Surveillance SystemAll Injury Program to report on the location of snakebites, activities of those bitten, and time of the year when bitten, but only included nonfatal injuries treated in hospital emergency departments (excluding urgent cares and physician offices). It did not provide local incidence rates by state.

\section{SNAKES}

New York is home to 3 venomous snakes: the timber rattlesnake, the northern copperhead, and the eastern massasauga. The most distributed of these is the timber rattlesnake (Crotalus horridus) with numerous reported occurrences throughout the state. ${ }^{11}$ The northern copperhead (Agkistrodon contortrix mokasen) is found primarily along the lower Hudson Valley south of Kingston and scattered through the Catskills. ${ }^{12}$ The eastern massasauga (Sistrurus catenatus catenatus) is found in only 2 small, disjoined populations: one just west of the city of Rochester and the other just northeast of the city of Syracuse. ${ }^{13}$

The northern copperhead, easily recognized by the coloration and shape of its head, is responsible for the largest percent $(36.2 \%)$ of reported venomous snakebites in the state during this period. The only other indigenous, venomous snake represented by name in this dataset is the timber rattlesnake, which is responsible for $4.3 \%$ of venomous snake bites during this period. The eastern massasauga is not reported by name during this period. Accurate identification of species can be difficult by the layperson, and even medical providers without significant experience may provide false identifications. The prairie rattlesnake (Crotalus viridis), the eastern diamondback rattlesnake (Crotalus adamanteus), and the water moccasin or cottonmouth (Angkistrodon piscivorus) are indicated as sources of envenomations although none of these 3 species are indigenous to the state. We believe these are either captive snakes or misidentified by reporters.

The categories of unspecified rattlesnakes (12 of 67; $18 \%$ of venomous bites), unspecified pit vipers (16 of $67 ; 24 \%$ ), and unspecified venomous snake (6 of 67;
9\%) found in our dataset are likely to include both indigenous snakes of the state and nonindigenous captives that could not be (or purposefully not for fear of reprisal) more specifically identified. The abstracted NPDS data do not report bites from any specific venomous snakes besides those in the Crotalinae family (pit vipers) although other families of snakes such as the Elapidae are a known source of envenomations in other studies such as this. ${ }^{4}$ The lack of reported Elapidae envenomations in our study is likely attributable to reporting bias as bites by exotic or captive snakes in this family were expected. Interestingly, multiple nonvenomous, nonnative snake genera or species are reported during this period.

\section{GEOGRAPHY}

The Central New York Regional PCC and the New York City PCC reported most of the envenomations and together accounted for almost $80 \%$ of all cases. Most envenomations were reported to the Central New York Regional PCC (36 of 67; 54\%), consistent with the geographic size of the center's catchment area and the normal distribution of venomous snakes across New York. Although smallest in geographic area covered, the New York City PCC was second only to the Central New York Regional PCC in referred envenomations with 28\% (19 of 67) of cases during this period. This is likely a function of the massive population served and could indicate a focus of exotic and other captive snakes because indigenous snakes of the state are unlikely to be encountered naturally in such a dense, urban setting. In fact, Jasper et al $^{14}$ surveyed potential snake owners in a single Northeast city (Philadelphia) and reported 74 different varieties of noninstitutional, captive, venomous snakes enumerated in the survey response.

Of the 19 venomous New York City PCC snakebites abstracted, the designation of "venomous, not otherwise specified" accounted for only 1 of their cases. The remainder were all reported to be snakes described in the Table. A significant number of all snakebites at this PCC (33 of 97; 34\%) were categorized as "Unknown (but considered nonvenomous)." It is possible that these specific records of bites, whether abstracted by us as venomous or not, may indicate either false reporting of an exotic species or false reporting by the victim as a wild species in spite of actually being an exotic species. Described differently, it is possible that an exotic Elapid owner could sustain a (found to be) dry bite by that venomous snake, go to an emergency department or other healthcare facility, report being bitten by a common garter snake, and be discharged as a minor outcome. Another consideration is that they may 
represent telephone-reported cases originating from nonurban locations (just north or east of the city but routed by the hotline to the New York City center) where indigenous snakes can be found.

\section{MANAGEMENT}

Data describing treatment are limited in NPDS. In this cohort, the use of antihistamines, antibiotics, and corticosteroids is described. Although the pretreatment of patients with corticosteroids or antihistamines as a means of preventing or muting allergic reactions has been described, the balance of the literature does not support the practice. ${ }^{15}$ The use of corticosteroids or antihistamines in patients not receiving antivenom (or as a substitution for it) is likely of little efficacy for the reduction of swelling or inflammation, ${ }^{16}$ although use of one or the other of these medications is reported in $2.1 \%$ (10 of 473) of nonvenomous bites (antihistamines, 2.1\%, 10 of 473; corticosteroids, $1.5 \%, 7$ of 473 ) and $10.1 \%$ of venomous bites (antihistamines, 10\%, 7 of 67 ; corticosteroids, $10 \%$, 7 of 67). The use of antibiotics is also controversial, ${ }^{17}$ but they were administered in $6 \%$ (29 of 473) of nonvenomous bites and 15\% (10 of 67) of venomous bites. Vaccination with tetanus toxin was not specified.

Males were more likely than females to be bitten by any snake, and were more likely than females to be bitten by venomous snakes as well. This is congruent with similar reports, ${ }^{5,6,8}$ and has been attributed to alcohol in previous epidemiologic studies. ${ }^{18}$

\section{LIMITATIONS}

One limitation of our dataset is that snake identification is reported by the case referrer, who may be a lay victim or healthcare worker without specific training in snake identification. Further, reporting to the PCC is entirely voluntary, resulting in a selection bias.

We acknowledge that a snakebite considered to be venomous is more likely to be reported than a bite by a common, nonvenomous snake. We also acknowledge that a large variety of nonindigenous venomous snakes are privately owned. ${ }^{14}$ Our data revealed that PCCs in New York take calls on nonindigenous and exotic snakes including several species of boas, pythons, and water snakes. Illegal snake keepers may be less likely to report an envenomation, or they may purposefully report a native species as the offender to avoid disclosure of an illegal, exotic specimen.

Another limitation is that we found many cases in our dataset in which the specific species of snake was not identified and required abstraction to estimate whether it was venomous or not. This limitation is inherent in the nature of PCC outcomes reporting. It may be instructive to understand the process of coding as performed in New York's PCCs. After a PCC case has been closed, its medical outcome code (as defined above) is entered by the PCC specialist based on their interpretation of the case. These codings are regularly reviewed for quality, but can be subject to inaccuracies. ${ }^{9}$ In our specific dataset, we found many more than expected medical outcomes coded as "moderate" and ascribe this to the strict definition that enables a PCC specialist to assign this outcome level if the patient receives an intravenous fluid or pain medication ("some kind of treatment required"). Further, it is not uncommon for large nonvenomous snakes like boas and pythons to cause soft tissue injury and require laceration repair or other symptomatic treatment, which may trigger a designation of "moderate."

Finally, our data are also limited by the closure of the Hudson Valley Regional Poison Center, which closed its operations in the first half of 2001. This PCC catchment area was then absorbed by others in the state, and its data were not available in our NPDS search. Any potential snakebite reports collected by them during the years 2000 and 2001 were thus not captured in our dataset, and may represent a slight underreporting in our analysis as a whole.

\section{Conclusions}

There were 473 documented snakebites during a 10-year period in the state of New York, 67 of which came from presumed venomous snakes. There were no fatalities and only 35 patients received antivenom. Similar to other studies, the majority of the patients were male.

\section{Acknowledgments}

We would like to thank the Medical and Managing Directors from the Western NY Poison Center, Ruth A. Lawrence Poison and Drug Information Center, New York City Poison Control Center, and Long Island Poison Center for allowing us to use their data.

\section{References}

1. Gold BS, Dart RC, Barish RA. Bites of venomous snakes. N Engl J Med. 2002;347:347-356.

2. Langley RL. Animal-related fatalities in the United States —an update. Wilderness Environ Med. 2005;16:67-74.

3. O’Neil ME, Mack KA, Gilchrist J, Wozniak EJ. Snakebite injuries treated in United States emergency departments, 2001-2004. Wilderness Environ Med. 2007;18:281-287.

4. Bronstein AC, Spyker DA, Cantilena LR Jr, Rumack BH, Dart RC. 2011 Annual report of the American Association of Poison Control Centers' National Poison Data System 
(NPDS): 29th Annual Report. Clin Toxicol (Phila). 2012; 50:911-1164.

5. Tanen D, Ruha A, Graeme K, Curry S. Epidemiology and hospital course of rattlesnake envenomations cared for at a tertiary referral center in Central Arizona. Acad Emerg Med. 2001;8:177-182.

6. Tokish JT, Benjamin J, Walter F. Crotalid envenomation: the southern Arizona experience. J Orthop Trauma. 2001;15:5-9.

7. Corneille MG, Larson S, Stewart RM, et al. A large single-center experience with treatment of patients with crotalid envenomations: outcomes with and evolution of antivenin therapy. Am J Surg. 2006;192:848-852.

8. White RR 4th, Weber RA. Poisonous snakebite in central Texas. Possible indicators for antivenin treatment. Ann Surg. 1991;213:466-472.

9. Poynton MR, Bennett H, Ellington L, Crouch BI, Caravati EM, Jasti S. Specialist discrimination of toxic exposure severity at a poison control center. Clin Toxicol (Phila). 2009;47:678-682.

10. Walter FG, Stolz U, Shirazi F, Walter CM, McNally J. Epidemiology of the reported severity of copperhead (Agkistrodon contortrix) snakebite. South Med J. 2012; 105:313-320.

11. New York State Department of Environmental Conservation. Timber Rattlesnake Distribution Map. Available at: http://www.dec.ny.gov/animals/44641.html. Accessed February 28, 2013.

12. New York State Department of Environmental Conservation. Northern Copperhead Distribution Map. Available at: http://www.dec.ny.gov/animals/44646.html. Accessed February 28, 2013.

13. New York State Department of Environmental Conservation. Eastern Massasauga Distribution Map. Available at: http://www.dec.ny.gov/animals/44643.html. Accessed February 28, 2013.

14. Jasper EH, Miller M, Neuburger KJ, Widder PC, Snyder JW, Lopez BL. Venomous snakebites in an urban area: what are the possibilities? Wilderness Environ Med. 2000;11:168-171.

15. Nuchpraryoon I, Garner P. Interventions for preventing reactions to snake antivenom. Cochrane Database Syst Rev. 2000(2):CD002153.

16. Schöttler W. Antihistamine, ACTH, cortisone, hydrocortisone and anesthetics in snake bite. Am J Trop Med Hyg. 1954;3:1083-1091.

17. LoVecchio F, Klemens J, Welch S, Rodriguez R. Antibiotics after rattlesnake envenomation. J Emerg Med. 2002; 23:327-328.

18. Morandi N, Williams J. Snakebite injuries: contributing factors and intentionality of exposure. Wilderness Environ Med. 1997;8:152-155. 